\title{
In the Field
}

\section{Transferable Skills in the Information Profession: Experiences in the Archives and Information Management Fields}

The Master of Library and Information Science (MLIS) degree features key benefits, such as the transferable skills obtained, which provide students with the ability to manoeuvre and adapt to diverse work environments. The opportunity to work in two different co-op positions during my time in the MLIS program at Western University has allowed me to see these transferable skills come to fruition. From maximizing patrons' access to archival documents as an intern with the University of Waterloo's Special Collection \& Archives (SCA) department to organizing and utilizing information assets as an information management (IM) analyst with the Federal Economic Development Agency for Southern Ontario (FedDev Ontario), I gained insight into the most beneficial

skills for a future career as an information professional. I discovered that communicating with stakeholders, understanding the trends of the profession, and possessing the skills to utilize metadata effectively are core competencies in providing the community with access to information resources.

A common requirement of my co-op positions was understanding stakeholders, including internal clients and external patrons, in order to provide effective services and to maximize access to information resources. With SCA, the patrons' perspectives helped shape the way archival collections were organized. One of the projects I worked on entailed organizing hundreds of film negatives and describing them. Since there was no apparent order to this material, understanding patrons' perspectives shaped how 
these records should be organized. A logical order would be based on chronology and geographic locations since patrons commonly use these topics to access records. Similarly, when I was working with the IM team at FedDev Ontario, it was important to consider the language used when speaking with clients to not only avoid jargon, but also to increase endorsement for IM projects and ideas. For instance, to provide the most suitable service, being aware of the positions and needs of users was pertinent when creating pamphlets on IM best practices. When creating these guides, it was essential for the procedures to be straightforward and use non-technical language to increase both the readability of materials for relevant stakeholders and the spread of knowledge throughout the agency. Hence, the pamphlets helped encourage internal clients to comply with IM procedures to facilitate efficient retrieval and access to information. Understanding and adapting to the users' perspectives was a crucial skill I employed in both of my co-op positions. This skill was important for increasing access to information through improving the searchability of records.

Whether they are working in the IM or archival fields, information professionals should always inform themselves of current and emerging trends. During my position with SCA, for example, students were heavily encouraged to join professional organizations, such as the Archives Association of Ontario (AAO). Being a part of professional communities provides opportunities to connect with peers through conferences and workshops. The AAO has also provided resources for recent developments in the field, such as for the handling of archival materials related to Indigenous communities in light of the calls to action of the Truth and Reconciliation Commission (Archives Association of Ontario (AAO), n.d.). Similarly, my co-op with 
FedDev Ontario encouraged opportunities for learning that allowed the team to share knowledge of trends in the field. For instance, there were seminars held by the Canadian School of Public Service that addressed the use of new emerging technologies, including machine learning as a means to automatically apply labels and keywords to describe the content of records. Additionally, one of my projects as an IM analyst was researching different records management systems and preparing a report to raise the team's awareness and understanding of technologies currently available. Both of my co-ops taught me that it is essential for information professionals to stay abreast of new trends to improve access to information resources for clients and patrons.

During my two co-op terms, I also discovered the importance of creating accurate and effective metadata. With SCA, metadata assisted in the search and retrieval of archival records and provided patrons with the context behind archival materials while they browsed the SCA's database of holdings. Accurate metadata is necessary so that patrons can search for certain archival records and gain a thorough understanding of the materials before deciding if visiting the archives in person is worth their time and effort. The metadata elements describing the record content include the physical dimensions, number of records, time periods, geographical information, and names of individuals or organizations involved in the creation of the archival records. Likewise, accurate metadata is necessary for the retention and classification of records for IM. Attributes like the date, year, file numbers, and program are required to understand the retention period and to properly dispose of records in accordance with guidelines and legislation. Additionally, ensuring that naming conventions are consistent in the 
metadata is essential so that all captured information accurately reflects the course of business, including when names, programs, or personnel change over time. In both the archives and IM fields, my co-op terms highlighted the benefits of well-executed metadata for records in terms of not only understanding what content records hold, but also making it easier for users to access and utilize information assets.

Overall, implementing patrons' perspectives into our practice, using the latest trends and technologies, and producing purposeful and effective metadata are core competencies in the information field. Working in different environments provided me with a solid foundation in understanding the transferability of essential skills and knowledge in the information profession. Although the two co-op positions had different motivations and aims, many transferable skills applied to both environments. The core competencies discussed in this piece are useful for a career in this profession because, although the setting may change, the most important responsibility held by an information professional is to connect communities to information resources.

\section{Paulina Hem}

Hem, P. (2020). Transferable skills in the information profession: Experiences in the archives and information management fields. Emerging Library \& Information Perspectives, 3, 221-224. https://doi.org/10.5206/elip.v3i1.8533 